\title{
CONTRIBUIÇÃO DA PSICOLOGIA AMBIENTAL PARA A POLÍTICA DE CONSTRUÇÃO DE MORADIAS
}

\author{
Yvonne Bernard ${ }^{1}$ \\ Centro Nacional de Pesquisas Científica da França
}

$O$ artigo parte de a previsão do futuro depender da observação $e$ avaliação das práticas atuais e do método de como obtê-las. Como responder à questão de como conceber, construir ou transformar as moradias que deverão durar um tempo suficientemente longo enquanto que, durante este tempo, os modos de vida sofrerão modificações importantes? Propõe a consideração de várias transformações como as de: tamanho e composição do grupo doméstico; tempos sociais; trabalho feminino; papéis tradicionais masculinos e feminino; atividades domésticas; autonomia familiar; sociabilidade; imagem e práticas do corpo; conforto. $O$ sentimento de bem-estar depende igualmente de como são satisfeitas exigências de ordem psicológica.

Descritores: Habitação. Psicologia ambiental. Comportamento coletivo. Modo de vida. Papel social. Sociabilidade. Conforto humano.

$\mathrm{O}$

s pesquisadores, em Ciências Sociais e, particularmente, os psicólogos, têm a missão de clarear as decisões que serão tomadas pelos políticos. Uma das maneiras de clarear as decisões consiste em formular previsões. Não se trata de afirmar ou de negar que tal evento produzir-se-á, mas de

1 Diretora de Pesquisa do Conselho Nacional de Pesquisa da França (CNRS); atividades de pesquis a e ensino no Laboratório de Psicologia do Ambiente, Paris V; especialista nos temas Urbanismo -Arquitetura-Ambiente e Evolução dos Modos de Vida e dos Modos de Morar. Endereço eletrônico: ybernard@ noos.fr

Psicologia USP, 2005, 16(1/2), 213-222 
estimar as possibilidades de sua produção. Uma previsão é uma afirmação probabilística ligada a um grau de confiança relativamente elevado.

Um dos modos de acessar a previsão é observar as práticas atuais e avaliar as chances que elas têm de perdurar, de se modificar ou de desaparecer. Prever o futuro a partir do conhecimento que se tem das práticas atuais supõe aceitar a hipótese de haver uma lógica nas práticas passível de ser interpretada com referência a um certo número de variáveis que caracterizam o indivíduo ou o casal. Esta compreensão e esta avaliação dos determinismos podem permitir antecipar a estabilidade ou, ao contrário, a mudança das práticas.

As previsões mais confiáveis se referem a certas variáveis sócioeconômicas das quais é possível prever a evolução, de modo razoável, a curto ou médio prazo. Isto é o que ocorre com a modificação do grupo doméstico, com a redução do tempo de trabalho, com a progressão do trabalho feminino. Pode-se, igualmente, inserir nesta categoria a previsão tecnológica. O desenvolvimento muito rápido dos meios de comunicação à distância pode permitir pensar que se vai desenvolver o trabalho à domicílio com as consequiências que isto acarreta. Algumas destas variáveis, por exemplo, o aumento do número de pessoas solitárias, têm, sobretudo, um efeito sobre a política habitacional. No que se refere à modificação das práticas, se for possível demonstrar que as variáveis cuja evolução é passível de ser prevista a curto prazo têm um efeito sobre o modo de habitar como, por exemplo, a modificação dos tempos sociais ou de uma nova relação com o trabalho, poder-se-á, então, antecipar uma modificação nos usos.

Uma segunda maneira de formular previsões pode consistir na análise do comportamento de grupos que, mesmo se o seu número é pequeno, contribuem grandemente para a inovação social. Pode-se, neste caso, falar preferencialmente de antecipação. Faz-se, então, a hipótese de que estes grupos constituem modelos cujos comportamentos vão progressivamente difundirse no conjunto do corpo social. Esta hipótese pode ser profícua se a população estudada tiver uma especificidade ligada a uma mudança previsível nos fatores da sociedade. Uma pesquisa sobre os pioneiros do "tele-trabalho" e a maneira como eles organizam seu espaço doméstico seria, por exemplo, de 
grande interesse. A hipótese se revela muito mais frágil quando se trata de comportamentos que correspondem a mudanças de atitudes ou de valores. Com efeito, a transmissão dos modelos pode se realizar de maneira vertical sob a forma de educação ou por intermédio de um modelo social tomado como referência. Mas existem, igualmente, modos de transmissão horizontal, fenômenos de moda, com contornos muito mais fluidos, com evolução mais rápida e, devido a isto, mais difíceis de serem analisados. No contexto de pesquisas que realizamos sobre as práticas do habitar, pudemos mostrar que os comportamentos ligados a uma transformação de atitudes ou de vabres como, por exemplo, a abertura do espaço privado, eram processos com evolução lenta e sobre os quais a origem social tinha um papel considerável.

O perigo é o mesmo quando se projeta a evolução de um país a partir do comportamento de outros países considerados precursores (ex.: países nórdicos, Holanda) e que se coloca a questão de saber se as diferenças observadas são devidas a especificidades culturais ou a simples defasagens. É preciso, a este respeito, sublinhar que, quanto maior o refinamento dos ind icadores, mais aparecem especificidades, donde há a necessidade de completar, de enriquecer e de matizar os resultados estatísticos com trabalhos de tipo antropológico.

Seria igualmente desejável a propósito de certos temas, como a mobilidade residencial e, de uma maneira mais geral, a propósito dos comportamentos que supõem estratégias, que tivéssemos pelo menos a escolha de prosseguir com estudos longitudinais. Os estudos estatísticos apreendem situações em um momento, mas não permitem fazer hipóteses sobre os processos que os produzem e que os transformam. Seria muito importante ter estudos de tipo autobiográfico para reconstituir as estratégias domésticas.

\section{Direções em que a Psicologia Ambiental deve se desenvolver}

Uma das questões mais freqüentemente colocadas aos psicólogos em Psicologia Ambiental pode ser resumida assim: 
como conceber, construir ou transformar as moradias que sabemos que deverão durar um tempo suficientemente longo enquanto que, durante este tempo, os modos de vida terão fortes chances de sofrer modificações importantes?

Pensamos que uma análise das práticas do morador de hoje é capaz de trazer alguns elementos de resposta a esta questão. Com efeito, se nós não vivemos mais como antes, na maioria dos casos, nós moramos o mais frequientemente como antes. Como é resolvida esta contradição? Que estratégias utiliza o morador para adaptar seu habitat, geralmente de concepção tradicional, ao seu modo de vida atual?

As práticas do habitar podem ser determinadas por três tipos de fatores:

- fatores com predominância psicológica, como a personalidade de um indivíduo ou a singularidade de um grupo familiar. As experiências residenciais vividas pelos sujeitos, os hábitos adquiridos na infância, a importância simbólica de certos objetos ou de certos comportamentos podem ser igualmente determinantes na maneira de ocupar o espaço;

- fatores ambientais que caracterizam o habitat e seu contexto: a situação geográfica, o tamanho da unidade urbana, o tipo de habitat, a distribuição do espaço da moradia permitem ou impedem certas atividades, brecam ou favorecem a satisfação das necessidades necessárias ao equilíbrio familiar ou pessoal;

- fatores demográficos e socioculturais que intervêm nas escolhas e nos comportamentos do morador por meio do sistema de normas ou de valores que caracterizam o grupo social ao qual ele pertence.

As práticas do habitar são o resultado da interação entre esses diferentes fatores evocados.

- se o interesse prioritário se referir aos fatores psicológicos, privilegiar-se-ão métodos de tipo qualitativo baseados em entrevistas ou técnicas de observação direta; 
- se o interesse for por fatores ambientais, poder-se-á antes recorrer a estudos de caso ou a monografias. Na França, numerosos estudos descreveram o comportamento dos moradores de certos tipos de habitat ou de certos bairros;

- finalmente os pesquisadores cujo objetivo essencial é a análise dos determinantes socioculturais que regem as práticas do habitar baseiam-se em grandes investigações.

Tipos de questões susceptíveis de serem clareadas por grandes investigações

1. Estaremos assistindo a uma homogeneização maciça das práticas domésticas ou, ao contrário, a despeito da melhoria geral do nível de vida e das condições da moradia, subsistem ainda diferenças sensíveis nas maneiras de habitar?

2. Se estas diferenças existem, quais são as variáveis sociológicas susceptíveis de explicá-las?

A título de sugestão, um certo número de temas podem ser evocados para tentar caracterizar a evolução de modos de vida que irão modificar notavelmente o uso da moradia, que serão apresentados a seguir.

\section{Modificação do tamanho e da composição do grupo doméstico}

Desde alguns anos, assiste-se a uma modificação sensível do grupo doméstico ligada, por sua vez, a variáveis demográficas (aumento da duração da vida, baixa da natalidade) e ao questionamento de certos valores tradicionais (família, casamento...). Esta modificação se traduz principalmente por um aumento significativo do número de pessoas que vivem sozinhas a título definitivo ou provisório assim como do número de famílias monoparentais. 


\section{Modificação dos tempos sociais}

Novas possibilidades de se estruturar a jornada de trabalho (jornada contínua), a redução do tempo de transporte (utilização de novos equipamentos), o aumento de pequenas férias. Na França, a redução recente do tempo de trabalho permite supor que se passa mais tempo no interior da moradia e, em particular, se tem mais tempo para o lazer. Como são organizados no habitat os espaços consagrados ao lazer, estes podendo ser coletivos ou individuais e variar em função das horas da jornada e dos dias da semana?

Desenvolvimento do trabalho feminino e transformação dos papéis tradicionais masculinos e femininos

Se bem que os resultados da últimas pesquisas sobre as planilhas-deuso-do-tempo deixem uma dúvida sobre esta hipótese prospectiva, pode-se esperar que se assiste a uma questionamento progressivo da partilha tradicional dos papéis. A participação dos homens nas tarefas domésticas é susceptível de modificar os espaços outrora reservados unicamente às mulheres? A organização e o equipamento da cozinha, o lugar que ela ocupa em relação aos demais cômodos podem ser indicadores interessantes da transformação do papel feminino.

\section{Transformações das atividades domésticas}

O progresso constante dos equipamentos domésticos deveria modificar consideravelmente a natureza das tarefas domésticas e reduzir - mas isto está longe de ser sempre verificado - o tempo que lhes é consagrado. Uma das mudanças mais importantes reside, sem dúvida, na liberdade de protelar e programar a compra e a preparação da alimentação. Como esta liberdade se traduz e como ela modifica os espaços de estocagem, de preparação e, sobretudo, de consumo? A refeição "à la carte", suporte publicitário de produtos congelados, está ocasionando uma desestruturação da refeição familiar 
e, do mesmo modo, assistimos ao desaparecimento do lugar onde ela era outrora consumida? A mesa tradicionalmente situada no meio da sala de jantar foi substituída por pequenas mesa móveis na proximidade da televisão ou do canto do lazer?

\section{Novas formas de sociabilidade}

O modelo tradicional de convívio que supunha um espaço de recepção cuja organização era definida com referência a modelos culturais muito precisos, é substituído, cada vez mais freqüentemente, pelo menos em certos grupos sociais, por novas formas de encontro muito mais informais que deslocam, sem dúvida, as fronteiras do privado, da intimidade, mas podem estar modificando também a disposição das zonas concebidas para receber.

\section{Desenvolvimento da autonomia no seio do grupo familiar}

$\mathrm{Na}$ França, dificuldades cada vez maiores de inserção na vida ativa obrigam os jovens adultos a permanecer na casa de seus pais. Paralelamente, os adolescentes parecem reivindicar cada vez mais cedo a sua autonomia, Esta dupla conjunção, associada a uma ideologia latente de busca de satisfação do eu, encontrada também no casal, tem, possivelmente, uma influência na organização do espaço doméstico, lugar estratégico de negociação das práticas cotidianas. Com efeito, o partilhar o espaço não implica necessariamente a partilha das práticas e dos valores. Esta situação conduz a uma redução do espaço comum em detrimento dos espaços individualizados? Como se inscrevem, no espaço, os processos de diferenciação e de identificação culturais dos diferentes membros do grupo familiar?

\section{Uma nova imagem e novas práticas do corpo}

A publicidade e o discurso propõem uma nova imagem do corpo que se torna enquanto tal objeto de interesse e de atenção. Como esta evolução se traduz na moradia? O quarto outrora exclusivamente reservado ao sono e 
à sexualidade do casal é hoje utilizado de modo diferente? Assistimos a um retorno ao quarto-salão, lugar de vida coletiva onde as crianças são admitidas para brincar ou olhar a televisão? Os limites do pudor se modificaram suficientemente para a transformação do uso do banheiro que, lugar de exercícios físicos e de cuidados corporais, pode se tornar um novo espaço de comunicação?

\section{Uma nova imagem do conforto}

Se bem que existam ainda na França cerca de $15 \%$ de moradias que não têm o conforto mínimo, pode-se considerar que a melhoria do conforto no sentido mais amplo do termo não depende, freqüentemente hoje em dia, da utilização de equipamentos mas antes da melhoria do tamanho e da qualidade dos espaços da moradia. De um modo geral, os estudos sobre o conforto analisam-no em uma perspectiva do incômodo. Uma nova maneira de tratálo seria abordá-lo pela noção do bem-estar. Os comportamentos podem ser, com efeito, analisados não sob o ângulo da tolerância e da adaptação, mas sob o ângulo da otimização de uma situação. A otimização implica em um processo no qual os indivíduos modificam o seu meio, esforçando-se por estabelecer as condições que asseguram a satisfação de suas necessidades elementares, mas também a realização de seus desejos explícitos e implícitos.

Nesta perspectiva, o sentimento de bem-estar não depende apenas de elementos materiais, mas também da maneira como são satisfeitas exigências de ordem essencialmente psicológica mas cuja importância é capital para o equilíbrio dos moradores, Entre estas, pode-se citar, por exemplo: a necessidade de luz e de abertura para os espaços exteriores, e a necessidade de espaço pessoal. 
Bernard, Y. (2005). Contributions of environmental psychology to the housing. Psicologia USP, 16(1/2), 213-222.

\begin{abstract}
The article initially proposes that the prediction of the future depends on the observation and evaluation of current practices and on the method of obtaining them. How can we answer the question of how we should conceive, construct or transform the dwelling spaces that we know must last for a sufficiently long time while, during that time, our ways of life will probably undergo important modifications? The author proposes that we take into account, among others, the transformations: of size and composition of the domestic group; of social times; of women's work; of traditional male and female roles; of domestic activities; of family autonomy; of sociability; of body image and practices; of comfort. Thus, the feeling of well-being depends, in addition to material elements, on the way in which needs of an essentially psychological nature are satisfied.
\end{abstract}

Index terms: Housing. Environmental psychology. Collective behavior. Lifestyle. Social roles. Sociability. Human comfort.

Bernard, Y. (2005). Contribution de la psychologie de l'environnement a la politique de construction de logements. Psicologia USP, 16(1/2), 213222.

Résumé: L'article repose sur le fait que la prévision du futur dépend de l'observation et de l'évaluation des pratiques actuelles ainsi que sur la méthode d'obtention de ces pratiques. Comment répondre à la question, à savoir: comment concevoir, construire ou transformer les logements qui, à notre connaissance, devront durer un temps suffisamment long tenant compte des éventuelles et considérables modifications qui surgiront, durant ce temps, dans les modes de vie? L'auteur propose que l'on tienne compte, entre autres, des transformations de la taille et de la composition du groupe domestique; des temps sociaux; du travail féminin; des rôles traditionnels masculins et féminins; des activités domestiques; de l'autonomie familiale; de la sociabilité; de l'image et des pratiques du corps; du confort. Le sentiment de bien-être dépend ainsi non seulement des éléments matériels, mais aussi de la façon dont sont satisfaites les exigences d'ordre essentiellement psychologique. 
Mots-clés: Logis. Psychologie de l'environnement. Comportement collectif. Modes de vie. Rôles sociaux. Sociabilité. Confort humain.

Recebido em 5.04.2004

Revisto e encaminhado em 23.02.2005

Aceito em: 7.03.2005 